\title{
Adsorption of 2,4,6-trichlorophenol by multi-walled carbon nanotubes as affected by $\mathrm{Cu}(\mathrm{II})$
}

\author{
Guang-Cai Chen ${ }^{a, b}$, Xiao-Quan Shan ${ }^{a, *}$, Yu-Sheng Wang ${ }^{a}$, Bei Wen ${ }^{a}$, Zhi-Guo Pei ${ }^{a}$, \\ Ya-Ning Xiec, Tao Liu ${ }^{c}$, Joseph J. Pignatello ${ }^{d}$
}

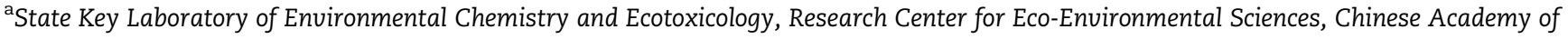
Sciences, 18 Shuanqing Road, Haidian District, Beijing 100085, China

${ }^{\mathrm{b}}$ Research Institute of Subtropical Forestry, Chinese Academy of Forestry, Fuyang, Zhejiang 311400, China

${ }^{\mathrm{c} B e i j i n g ~ S y n c h r o t r o n ~ R a d i a t i o n ~ L a b o r a t o r y, ~ I n s t i t u t e ~ o f ~ H i g h ~ E n e r g y ~ P h y s i c s, ~ C h i n e s e ~ A c a d e m y ~ o f ~ S c i e n c e s, ~ B e i j i n g ~ 100049, ~ C h i n a ~}$

${ }^{\mathrm{d} D e p a r t m e n t}$ of Soil and Water, Connecticut Agricultural Experiment Station, 123 Huntington Street, New Haven, CT 06504-1106, USA

\section{A R T I C L E I N F O}

\section{Article history:}

Received 17 November 2008

Received in revised form

27 February 2009

Accepted 2 March 2009

Published online 11 March 2009

\section{Keywords:}

2,4,6-Trichlorophenol

$\mathrm{Cu}(\mathrm{II})$

Multi-walled carbon nanotubes Adsorption

\begin{abstract}
A B S T R A C T
Adsorption equilibrium of 2,4,6-trichlorophenol (TCP) on multi-walled carbon nanotubes (MWCNTs) was investigated to explore the possibility of using MWCNTs for concentration, detection and removal of TCP from contaminated water. The adsorption of TCP on MWCNTs at pH 4 was nonlinear, reversible and best fit by a Polanyi-Manes model. Oxidation treatment increased surface area and introduced hydrophilic carboxylic groups to the defect sites of MWCNTs, hence increased the sorption of TCP and $\mathrm{Cu}(\mathrm{II})$ individually. $\mathrm{Cu}$ (II) suppressed the sorption of TCP on oxidized MWCNTs15A, but had little effect on asgrown MWCNTs15. TCP had no influence on $\mathrm{Cu}(\mathrm{II})$ sorption to either. The mechanisms of $\mathrm{Cu}$ (II) suppression effect on TCP adsorption are ascribed to the formation of surface complexes of $\mathrm{Cu}$ (II), which was verified by X-ray absorption spectroscopy. $\mathrm{Cu}$ (II) exerts a cross-linking effect of functional groups on adjacent tubes, creating a more tightly knit bundle and suppressing the condensation of TCP in the pore spaces between the tubes. The large hydration sphere around surface complexes of $\mathrm{Cu}$ (II) may also intrude or shield hydrophilic sites, leading to the "crowding out" of TCP around the $\mathrm{Cu}$ (II)-complexed sites. (c) 2009 Elsevier Ltd. All rights reserved.
\end{abstract}

\section{Introduction}

Carbon nanotubes (CNTs) are considered to be superior adsorbents of pollutants due to their unique properties and relative high reactivity. Their high adsorption capacities on removal of heavy metals (Li et al., 2002, 2003a; Lu and Chiu, 2006; Wang et al., 2005) and toxic organic chemicals (Chin et al., 2007; Long and Yang, 2001; Lu et al., 2005; Yang et al., 2006a,b; Yang and Xing, 2007) from water have been proved extensively.

The sorption capacity of CNTs can be modified by oxidative treatment with $\mathrm{NaOCl}, \mathrm{H}_{2} \mathrm{O}_{2}, \mathrm{KMnO}_{4}$ or $\mathrm{HNO}_{3}$ (Li et al., 2003a; $\mathrm{Lu}$ and Chiu, 2006; Wang et al., 2005). Oxidation removes impurities and hemispherical caps, hence increases surface area and introduces oxygen-containing functional groups (Li et al., 2003a; Lu and Chiu, 2006; Wang et al., 2005). Modification of the structure and surface properties of CNTs affected sorption capacity and sorption mechanisms of metals and organic chemicals (Li et al., 2003a; Lu and Chiu, 2006; Wang et al., 2005; Lu et al., 2005; Chin et al., 2007; Cho et al., 2008). The adsorption capacity of $\mathrm{Cu}^{2+}$ at a given $\mathrm{pH}$ followed the order NaOClmodified $\mathrm{CNTs}>\mathrm{HNO}_{3}$-modified $\mathrm{CNTs}>$ as-produced CNTs (Wu, 2007). The extraordinary increase in sorption capacity and decrease in desorption rate of ${ }^{243} \mathrm{Am}$ (III) after oxidation of

\footnotetext{
* Corresponding author. Tel.: +8610 62923560; fax: +861062923563.

E-mail address: xiaoquan@rcees.ac.cn (X.-Q. Shan).

0043-1354/\$ - see front matter ๔ 2009 Elsevier Ltd. All rights reserved. doi:10.1016/j.watres.2009.03.002
} 
Table 1 - Selected structural properties of MWCNTs.

\begin{tabular}{lccccccccc} 
Carbons & Outer diameter $(\mathrm{nm})$ & Inner diameter $(\mathrm{nm})$ & Length $(\mu \mathrm{m})$ & Purity $(\%)$ & $\begin{array}{c}\mathrm{A}_{\text {surf }} \\
\left(\mathrm{m}^{2} \mathrm{~g}^{-1}\right)\end{array}$ & $\begin{array}{c}\mathrm{V}_{\text {meso }} \\
\left(\mathrm{cc} \mathrm{g}^{-1}\right)\end{array}$ & $\begin{array}{c}\mathrm{V}_{\text {micro }} \\
\left(\mathrm{cc} \mathrm{g}^{-1}\right)\end{array}$ & $\begin{array}{c}\text { Oxygen content } \\
(\mathrm{atom} \%)\end{array}$ \\
\hline MWCNTs8 & $<8$ & $2-5$ & $10-30$ & $95+$ & 559 & 1.69 & 0.085 & $\mathrm{ND}$ \\
MWCNTs15A & $10-15$ & $5-8$ & $10-30$ & $95+$ & 279 & 0.57 & 0.026 & 3.92 \\
MWCNTs15 & $10-15$ & $5-8$ & $10-30$ & $90+$ & 181 & 0.41 & 0.016 & 1.52 \\
MWCNTs20 & $10-20$ & $5-10$ & $10-30$ & $95+$ & 167 & 0.55 & 0.016 & ND \\
MWCNTs30 & $30-50$ & $5-15$ & $10-20$ & $95+$ & 91 & 0.30 & ND & ND \\
MWCNTs50 & $>50$ & $5-15$ & $10-20$ & $95+$ & 68 & 0.16 & ND & ND \\
\hline
\end{tabular}

a ND, Not detected.

multi-walled carbon nanotubes (MWCNTs) suggested that chemisorption rather than physisorption and/or ion-exchange is the main sorption mechanism (Wang et al., 2005). The modified MWCNTs have different adsorption affinities for different metal ions, a study on the individual and competitive adsorption capacities of $\mathrm{Pb}^{2+}, \mathrm{Cu}^{2+}$ and $\mathrm{Cd}^{2+}$ showed the adsorption affinity in the order of $\mathrm{Pb}^{2+}>\mathrm{Cu}^{2+}>\mathrm{Cd}^{2+}$ (Li et al., 2003b). Nitric acid treatment of single-walled carbon nanotubes (SWCNTs) increased sorption of $p$-xylene, while it decreased sorption of o-xylene, suggesting that sorption depends on the substitution pattern on the ring and the density of oxygen-containing groups on the surface (Chin et al., 2007). Adsorption of naphthalene to MWCNTs decreased linearly with surface O content (Cho et al., 2008). X-ray photoelectron spectroscopy showed clearly that tetracene and phenanthrene molecules efficiently coated the external surface of SWCNTs. The adsorption of tetracene and phenanthrene caused a significantly higher frequency shift in radial breathing mode of the Raman spectrum of SWCNTs, indicating face-to-face adsorption with an intensive $\pi-\pi$ interaction between these polycyclic aromatic hydrocarbons (PAHs) and SWCNTs (Gotovac et al., 2007).

Most research on sorption of metals or organic compounds by CNTs has been on single-solute systems. However, contaminants often exist in mixtures in the environment, where they may affect each other's sorption. Heavy metals and organic contaminants coexist at many contaminated sites (Dai et al., 2007; Sprovieri et al., 2007), and coexisting

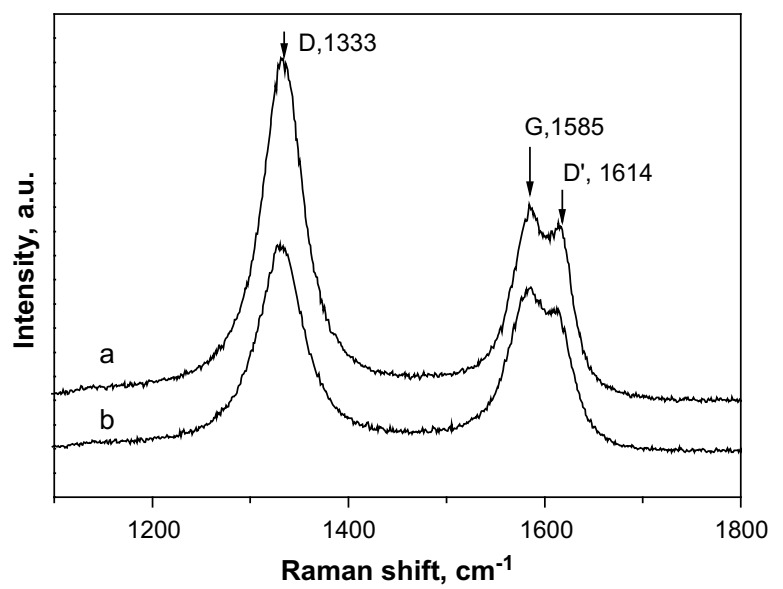

Fig. 1 - Raman spectra of MWCNTs15A (a) and MWCNTs15 (b). heavy metal ions affect the adsorption of organic contaminants to soil, peat and charcoal (Pei et al., 2006, 2007; Chen et al., 2007). A few studies have been reported on competitive sorption between metals (Li et al., 2003b) or between organic contaminants on CNTs (Yang et al., 2006b).

Chlorinated phenols, including 2,4,6-trichlorophenol (TCP), have been widely used in agriculture, wood preservation, and pulp bleaching (Makinen et al., 1993; Suntio et al., 1988; Yoshida et al., 1987). They are found in the emissions from fossil fuel combustion, municipal waste incineration, and chlorination of water containing phenol or certain aromatic acids with hypochlorite or during disinfection of water (Chaliha and Bhattacharyya, 2008). TCP has been listed as a priority pollutant by the USEPA (Keith and Telliard, 1979) and China (Zhou et al., 1991) due to its animal carcinogenicity (NCI, 1979), producing lymphomas, leukemia, and liver cancer via oral exposure through drinking water or food. Copper is an essential element for life at low concentration, but is toxic at high concentration. It commonly exists in the soil environment, especially in soil irrigated by wastewater in countries with high water shortage. It should be realized that copper and TCP may occur together in field irrigated by wastewater and ground water (Daughney and Fein, 1997; Mueller et al., 1989). Coexistence of copper and TCP may affect their fates in the environment, but little is known on how they interact with each other on MWCNTs.

The aim of this study was to investigate the effect of copper on the sorption of TCP and vice versa on MWCNTs. Raman, Fourier transform infrared (FTIR) and X-ray absorption spectroscopy (XAS) studies were used to probe structure, surface functional groups and coordination environments of copper on MWCNTs in order to reveal the mechanism of copper-TCP interactions on the surface of MWCNTs.

\section{Experimental}

\subsection{Materials}

TCP (>98\%) was purchased from Aldrich Chemical Co. Inc. TCP has a $\log K_{\text {ow }}$ of $3.67, \mathrm{pK}_{\mathrm{a}}$ of 6.1 and a water solubility $\mathrm{C}_{\mathrm{s}}$ of $300 \mathrm{mg} \mathrm{L}^{-1}(\mathrm{pH}<5)$ (Wightman and Fein, 1999). $\mathrm{Cu}\left(\mathrm{NO}_{3}\right)_{2}$ is of guaranteed reagent grade. Other chemicals are of analytical reagent grade or better.

MWCNTs with different diameters were purchased from Chengdu Organic Chemistry Co. Ltd, Chinese Academy of 


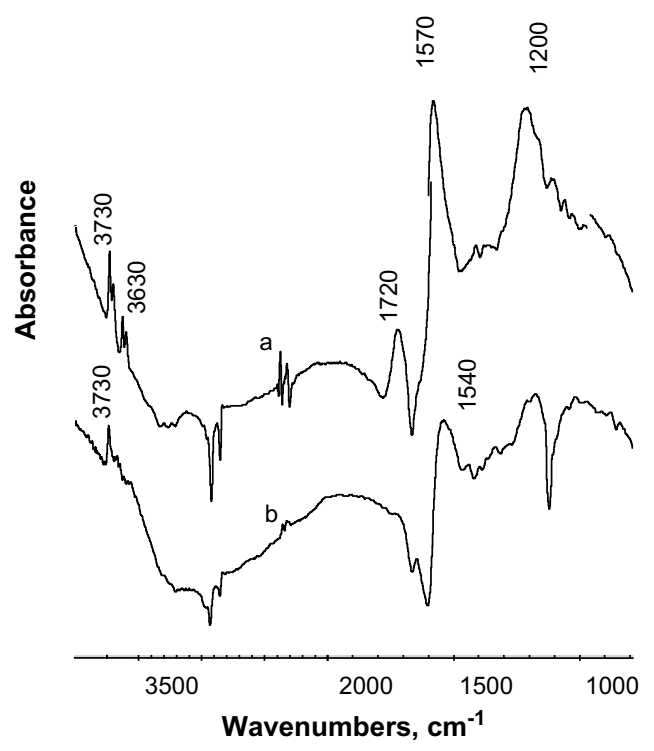

Fig. 2 - FTIR spectra of MWCNTs15A (a) and MWCNTs15 (b).

Sciences. The numbers after MWCNTs in Table 1 are their outer diameters. These MWCNTs were synthesized from ethylene/nitrogen $\left(\mathrm{C}_{2} \mathrm{H}_{4} / \mathrm{N}_{2}=3 / 2\right)$ mixture by chemical vapor deposition at $823 \mathrm{~K}$ using $\mathrm{Fe} / \mathrm{Al}_{2} \mathrm{O}_{3}$ as catalyst. MWCNTs15A refers to the material obtained after treating MWCNTs15 with $3 \mathrm{M}$ nitric acid to remove impurities and hemispherical caps (Rinzler et al., 1998). The mixture of $2 \mathrm{~g}$ as-grown MWCNTs and $400 \mathrm{~mL} 3 \mathrm{M}$ nitric acid was ultrasonically stirred for 24 hours. The suspension was filtrated and then rinsed with deionized water until the $\mathrm{pH}$ of the suspension reached about 6 and then was dried at $80^{\circ} \mathrm{C}$ (Rinzler et al., 1998; Wang et al., 2005).

The diameters of MWCNTs were determined by TEM. The surface area and pore volume were measured by nitrogen gas adsorption and desorption at $77 \mathrm{~K}$ with ASAP2000 (Micromeritics Instrument Corporation), which were calculated by multi-point BET, BJH, and DR methods, respectively. The micropore volume was measured by carbon dioxide sorption with Quantachrome instruments v2.2 and calculated with DFT method.

\subsection{Batch adsorption experiments}

Ten milligrams of MWCNTs were used for the sorption of TCP or $\mathrm{Cu}$ (II), while $20 \mathrm{mg}$ of MWCNTs were used for the coadsorption of $\mathrm{Cu}(\mathrm{II})$ and TCP. MWCNTs were combined with the test solute(s) dissolved in $20 \mathrm{~mL}$ deionized distilled water containing $0.01 \mathrm{~mol} \mathrm{~L}^{-1} \mathrm{NaNO}_{3}$ and $100 \mathrm{mgL}^{-1} \mathrm{NaN}_{3}$ as a biocide in $40 \mathrm{~mL}$ screw-cap glass vials sealed with Teflon screw caps. All sorption experiments were performed in triplicate except for the sorption isotherms of TCP and sorption kinetics of $\mathrm{Cu}$ (II), which were conducted in duplicate. The $\mathrm{pH}$ was adjusted to 4 where dissolved TCP is predominantly (>99.3\%) neutral, and where hydrolysis and precipitation of $\mathrm{Cu}$ (II) are negligible. This $\mathrm{pH}$ value is typical of the $\mathrm{pH}$ of red soil in southern China.

The vials were placed in a shaker at $20 \pm 0.5^{\circ} \mathrm{C}$. Sorption of TCP on MWCNTs reaches apparent equilibrium within 24 hours. To be conservative, an equilibration time of 48 hours was used routinely. After sample centrifugation $(2000 \times g$ for $20 \mathrm{~min}$ ), TCP in the liquid phase was determined by HPLC (HP 1100, Agilent Technologies) fitted with a diode array detector (DAD) at $220 \mathrm{~nm}$, and an extended polar selectivity reversedphase $\mathrm{C} 18$ column (15 $\mathrm{cm} \times 4.6 \mathrm{~mm}$ i.d.). Isocratic elution was performed at a flow rate of $0.7 \mathrm{~mL} \mathrm{~min}^{-1}$, the mobile phase was methanol/water (80\%:20\%). Cu(II) was determined by inductively coupled plasma-atomic emission spectrometry (ICP-AES, Perkin-Elmer) after filtration through a $0.45-\mu \mathrm{m}$ hydrophilic polyethersulfone membrane. Blank experiments indicated that recoveries of adsorbates without MWCNTs added were greater than $97 \%$ of their initial concentrations, indicating no significant losses or degradation or adsorbed by the glass vials in the time frame of the batch sorption study. Therefore, the adsorbed mass was calculated by the difference between initial and final equilibrium concentrations.

\subsection{XAS measurements and data analysis}

The X-ray Absorption Near-Edge Structure (XANES) and Extended X-ray Absorption Fine Structure (EXAFS) spectra were collected at Beijing Synchrotron Radiation Facility on 4W1B beamline. Electron beam energy was $2.2 \mathrm{GeV}$ with a storage ring beam current of $80 \mathrm{~mA}$. Sample preparation and data collection followed the methods described in our
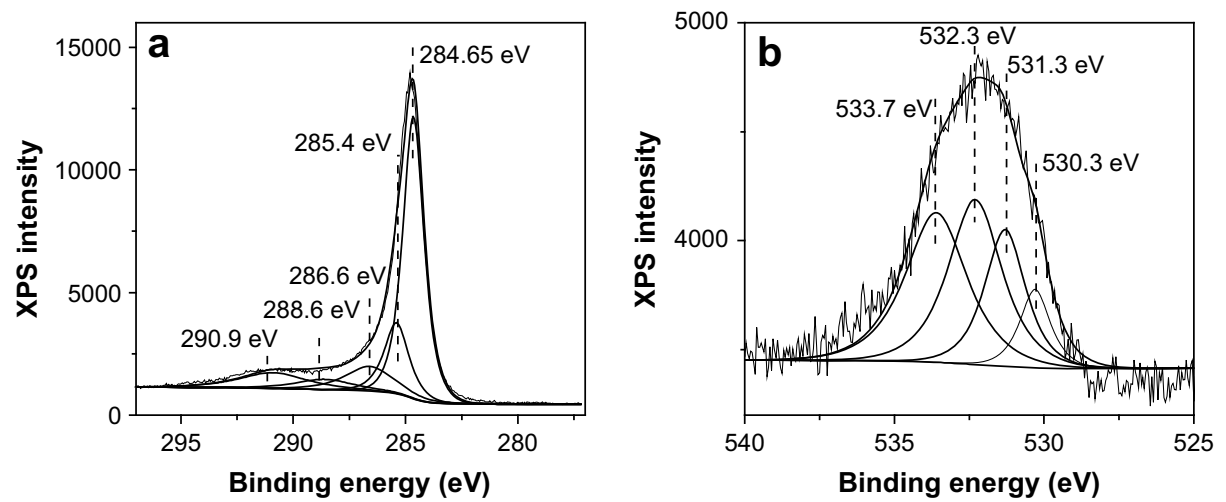

Fig. 3 - Deconvolution of the XPS C1s (a) and 01s (b) peaks of MWCNTs15A. 

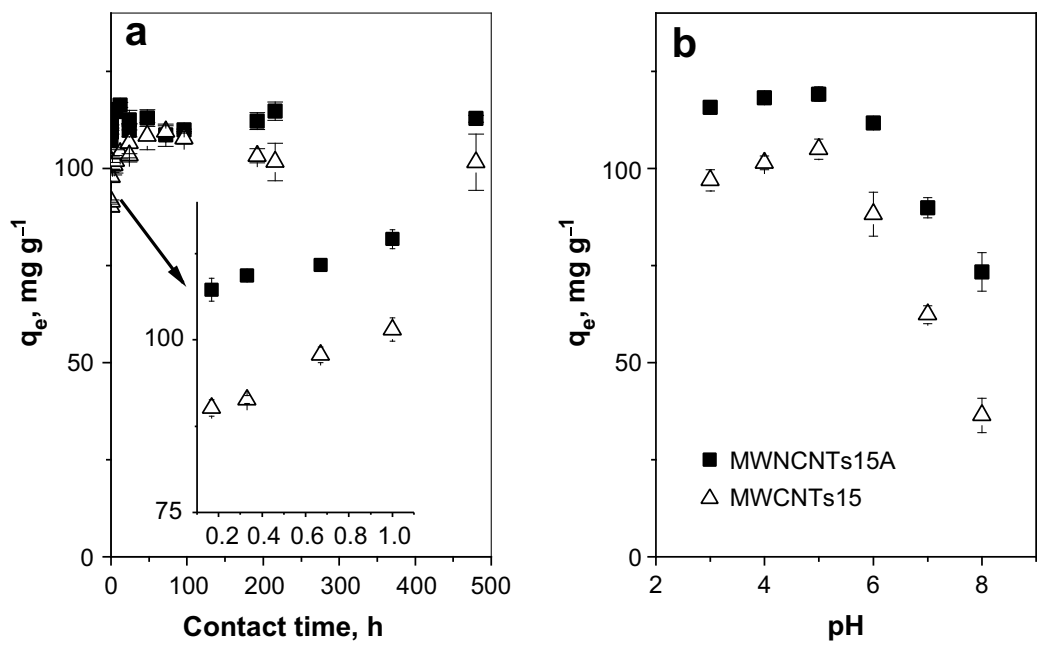

Fig. 4 - Effects of contact time (a, $10 \mathrm{mg}$ of MWCNTs and $120 \mathrm{mg} \mathrm{L}^{-1}$ of TCP in $20 \mathrm{~mL}$ of $0.01 \mathrm{M} \mathrm{NaNO}_{3}$ at pH 4 ) and pH (b, $10 \mathrm{mg}$ of MWCNTs and $120 \mathrm{mg} \mathrm{L}^{-1}$ of TCP in $20 \mathrm{~mL}$ of $0.01 \mathrm{M} \mathrm{NaNO}_{3}$ react for 48 hours) on the sorption of TCP by MWCNTs15A and MWCNTs15.

previous research (Pei et al., 2006). Briefly, data analysis was performed with WinXAS2.1 following background correction and normalization, Cubic spline, Fourier transformation and reverse Fourier transformation, and EXAFS fitting. In the fitting procedure, the coordination number was fixed for the reference compounds, while the Debye-Waller factor was fixed for samples. Phase shifts and backscattering amplitudes were obtained from the theoretical calculation using FEFF 7.0.

\section{Results and discussion}

\subsection{Characterizations of MWCNTs}

Selected structural properties of MWCNTs are listed in Table 1. MWCNTs15A, the product of nitric acid treatment of MWCNTs15, has a larger surface area and mesopore volume than MWCNTs15 due to the removal of amorphous carbon

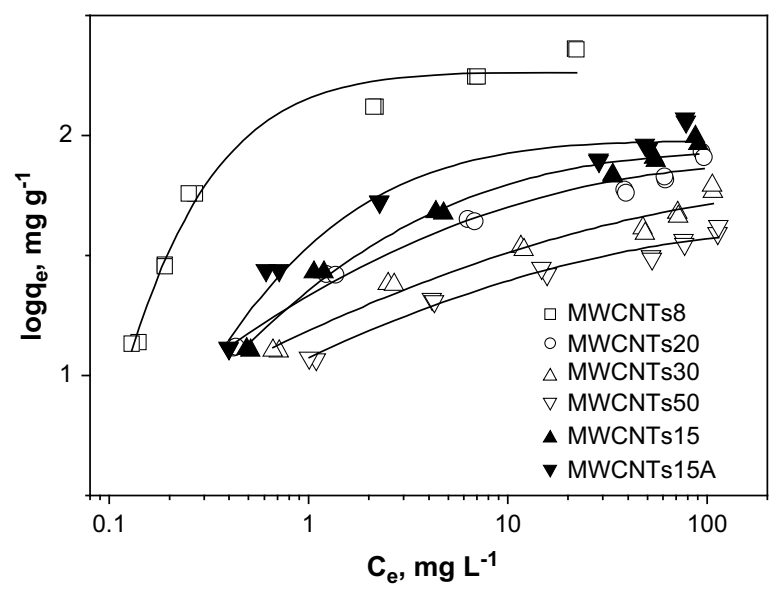

Fig. 5 - Fit of PMM to the sorption of TCP onto six MWCNTs. and hemispherical caps on the nanotubes (Li et al., 2002, 2003a; Ying et al., 2003).

Raman spectra of MWCNTs15 and MWCNTs15A (Fig. 1) show three characteristic peaks at around $1585 \mathrm{~cm}^{-1}$ ( $\mathrm{G}$ band), $1333 \mathrm{~cm}^{-1}$ (D band) and $1614 \mathrm{~cm}^{-1}$ ( $\mathrm{D}^{\prime}$ band). The $\mathrm{G}$ band originates from in-plane tangential stretching of the carboncarbon bonds in graphene sheets. The D band is due to defect sites in the hexagonal framework of walls of MWCNTs (Ying et al., 2003). The $\mathrm{D}^{\prime}$ band, which is a weak shoulder of the $G$ band, is induced by disorder and defects. Defect content is given by the ratio of $\mathrm{D}$ band to $\mathrm{G}$ band intensities (ID/IG). Nitric acid oxidative treatment increased ID/IG from 1.23 for MWCNTs15 to 1.68 for MWCNTs15A by eliminating amorphous carbon and modifying the outermost graphene layer of MWCNTs chemically. This finding is consistent with the results of Datsyuk et al. (2008) and Hsin et al. (2006).

The FTIR spectrum of MWCNTs15A (Fig. 2a) exhibits peaks at $1200 \mathrm{~cm}^{-1}$ (C-N stretch) resulting from $3 \mathrm{M}$ nitric acid treatment, $1570 \mathrm{~cm}^{-1}$ (asymmetric -COO- stretch), $1720 \mathrm{~cm}^{-1}$ ( $\mathrm{C}=\mathrm{O}$ stretch of keto or carboxyl groups), consistent with the results of Kim et al. (2007). It should be mentioned that the band at $1200 \mathrm{~cm}^{-1}$ can be referred to the symmetric strength vibration (-COO-) as well. Consistently a band at $1570 \mathrm{~cm}^{-1}$ appears in the FTIR, which is the asymmetric strength vibration (-COO-) (Schierz and Zanker, 2009). The spectrum of MWCNTs15 (Fig. 2b) shows a small peak at $1540 \mathrm{~cm}^{-1}$. The FTIR spectra indicate that nitric acid treatment introduced more oxygen-containing functional groups (Coleman et al., 2003; Wang et al., 2005) on the outermost surface and defect sites that increase the hydrophilicity of MWCNTs. In this case, the oxidative treatment not only "attacks" the carbon defect sites but also creates additional defects (Datsyuk et al., 2008).

X-ray photoelectron spectroscopy (XPS) also provides useful information on the nature of functional groups and also on the presence of defects on the nanotube surface. In Fig. 3, the XPS C1s and 01s peaks of MWCNTs15A are presented. Deconvolution of the C1s peak (Fig. 3a) resolved a main peak of 
Table 2 - Nonlinear sorption isotherm models.

\begin{tabular}{|c|c|c|}
\hline Model & Equation & Capacity term $^{a}$ \\
\hline $\begin{array}{l}\text { Freundlich } \\
\text { model }\end{array}$ & $q_{e}=K_{F} C_{e}^{N}$ & $\mathrm{~K}_{\mathrm{F}}\left(\mathrm{mg}^{1-\mathrm{N}} \mathrm{g}^{-1} \mathrm{~L}^{-\mathrm{N}}\right)$, Freundlich affinity coefficient; $\mathrm{N}$, Freundlich exponential coefficient \\
\hline $\begin{array}{l}\text { Langmuir } \\
\text { model }\end{array}$ & $q_{e}=Q^{0} b C_{e} /\left(1+b C_{e}\right)$ & $b\left(\mathrm{~L} \mathrm{mg}^{-1}\right)$, Langmuir constants \\
\hline $\begin{array}{l}\text { Dual mode } \\
\text { model }\end{array}$ & $q_{e}=Q^{0} b C_{e} /\left(1+b C_{e}\right)+K_{P} C_{e}$ & $K_{\mathrm{P}}\left(\mathrm{L} \mathrm{g}^{-1}\right)$, partition coefficient \\
\hline $\begin{array}{l}\text { Dual Langmuir } \\
\text { model }\end{array}$ & $\begin{array}{l}q_{\mathrm{e}}=\mathrm{Q}_{1}^{0} b_{1} \mathrm{C}_{\mathrm{e}} /\left(1+b_{1} \mathrm{C}_{\mathrm{e}}\right)+\mathrm{Q}_{2}^{0} b_{2} \mathrm{C}_{\mathrm{e}} / \\
\left(1+b_{2} \mathrm{C}_{\mathrm{e}}\right)\end{array}$ & $\begin{array}{l}\mathrm{Q}_{1}^{0}\left(\mathrm{mg} \mathrm{g}^{-1}\right) \text { and } \mathrm{Q}_{2}^{0}\left(\mathrm{mg} \mathrm{g}^{-1}\right) \text {, sorbed capacity of site populations } 1 \text { and } 2 \text {, respectively; } b_{1} \text { and } \\
b_{2}\left(\mathrm{~L} \mathrm{mg}^{-1}\right) \text {, affinity coefficient of site populations } 1 \text { and } 2 \text {, respectively }\end{array}$ \\
\hline $\begin{array}{l}\text { Polanyi-Manes } \\
\text { model }\end{array}$ & $\begin{array}{l}\log q_{\mathrm{e}}=\log Q^{0}+a\left(\varepsilon_{\mathrm{sw}} / \mathrm{V}_{\mathrm{s}}\right)^{b} \\
\varepsilon_{\mathrm{sw}}=R T \ln \left(C_{\mathrm{s}} / C_{\mathrm{e}}\right) \text { or } q_{\mathrm{e}}=\mathrm{Q}^{0} \mathrm{EXP} \\
\left(a^{*}\left(\varepsilon_{\mathrm{sw}} / \mathrm{V}_{\mathrm{s}}\right)^{b}\right)\end{array}$ & $\begin{array}{l}\varepsilon_{\text {sw }}\left(\mathrm{kJ} \mathrm{mol}^{-1}\right) \text {, effective adsorption potential; } \mathrm{V}_{\mathrm{s}}\left(\mathrm{cm}^{3} \mathrm{~mol}^{-1}\right) \text {, molar volume of solute; } \\
a\left(\left(\mathrm{~cm}^{3}\right)^{b+1}(\mathrm{~kg} \mathrm{~J})^{-b}\right) \text { and } b \text {, fitting parameters; } R\left(8.314 \times 10^{-3} \mathrm{~kJ}(\mathrm{~mol} \mathrm{~K})^{-1}\right) \text {, universal gas } \\
\text { constant; } \mathrm{T}(\mathrm{K}) \text {, absolute temperature potential }\end{array}$ \\
\hline
\end{tabular}

$\mathrm{sp}^{2} \mathrm{C}=\mathrm{C}(284.65 \mathrm{eV})$, attributed to the graphitic structure and a peak of $\mathrm{sp}^{3} \mathrm{C}-\mathrm{C}(285.4 \mathrm{eV})$ attributed to defects in the nanotube structure. Peaks of $\mathrm{C}-\mathrm{O}(288.6 \mathrm{eV}),>\mathrm{C}=\mathrm{O}(286.6 \mathrm{eV})$, and O-COO (290.9 eV) were assigned to carbon atoms attached to different oxygen-containing moieties. Deconvolution of the XPS O1s peak (Fig. 3b) confirmed the presence of $\mathrm{C}-\mathrm{O}-\mathrm{C}, \mathrm{C}-\mathrm{O}$, $\mathrm{C}-\mathrm{OH}$ at $\sim 533.7 \mathrm{eV}(\mathrm{C}-\mathrm{O}-\mathrm{C}, \mathrm{C}-\mathrm{O}, \mathrm{C}-\mathrm{OH}), \mathrm{C}=\mathrm{O}, \mathrm{O}-\mathrm{C}=\mathrm{O}$ at $\sim 532.3 \mathrm{eV}$, isolated $-\mathrm{OH}, \mathrm{C}=\mathrm{O}, \mathrm{O}-\mathrm{C}=\mathrm{O}$ at $\sim 531.3 \mathrm{eV}$ and O-physically absorbed, or carbonates at $\sim 530.3 \mathrm{eV}$ (Datsyuk et al., 2008).

\subsection{Adsorption of TCP}

The effects of contact time and $\mathrm{pH}$ on the sorption of TCP are given in Fig. 4. The sorption of TCP is very fast in the first 1 hour and reaches apparent equilibrium within 24 hours (Fig. 4a). The sorption of TCP is $\mathrm{pH}$ dependent. Sorption is approximately constant over the $\mathrm{pH}$ range of 3-5 and then declines in the $\mathrm{pH}$ range of $5-8$ as TCP becomes ionized (Fig. 4b). Considering the $\mathrm{pK}_{\mathrm{a}}$ value of 6.1 (Wightman and Fein, 1999) for TCP, it appears that the greater sorption at low $\mathrm{pH}$ 3-5 may be due to the predominant species of neutral TCP. An increase of solution $\mathrm{pH}$ value of 5-8 increased the fraction of negatively charged TCP species and the dissociation of functional groups of adsorbents (Pei et al., 2007; Wu, 2007). Therefore, the repulsion of anionic TCP with the negatively charged surfaces of MWCNTs makes sorption unfavorable. Furthermore, solubility of TCP increases rapidly with $\mathrm{pH}$ above 6 (Wightman and Fein, 1999). The increase in solubility decreases the driving force for sorption of TCP on MWCNTs.

There are some differences in the adsorbed TCP between MWCNTs15A and MWCNTs15 as affected by contact time and $\mathrm{pH}$ (the inset of Fig. $4 \mathrm{a}$ and b). The modified MWCNTs15A is more hydrophilic and hardly amenable for organic substances, thus less TCP sorption onto MWCNTs15A is expected (Cho et al., 2008). However, oxidation treatment also increased the surface area and $V_{\text {meso }}$ (Table 1), leading to the increased sorption of TCP. Overall, MWCNTs15A has higher adsorption affinity for TCP than does MWCNTs15 (Fig. 4).

The single-solute sorption isotherms of TCP at $\mathrm{pH} 4$ are shown in Fig. 5. Five nonlinear sorption isotherm models (Table 2) of Freundlich (FM) (Freundlich, 1906), Langmuir (LM) (Langmuir, 1916), Dual Mode (DMM) (Xing and Pignatello, 1997), Dual Langmuir (DLM) (Sander and Pignatello, 2005) and Polanyi-Manes models (PMM) (Manes, 1980) were tested to fit the sorption of TCP on six MWCNTs. The PMM model fits all of the sorption isotherms well with the lowest MWSE (Fig. 5, Table 3). Other models were tested and rejected for the following reasons, FM and LM models failed to adequately describe the isotherms and greatly underestimated $q$ at low equilibrium concentration $\left(C_{e}\right)$, DMM and DLM models fit the isotherms well in most cases with the exception of lower concentration end of the isotherms of MWCNTs8 and MWCNTs15A (Fig. S1, Supporting information). Hence the following discussion is based on the adsorption parameters calculated from PMM fitting.

Table 3 - Results of PMM fit to the sorption isotherms of TCP on MWCNTs.

\begin{tabular}{lccccc} 
& $\log Q^{0}\left(\mathrm{mg} \mathrm{g}^{-1}\right)$ & $a\left[\left(\mathrm{~cm}^{3}\right)^{b+1}(\mathrm{~kg} \mathrm{~J})^{-b}\right]$ & $b$ & $\mathrm{MWSE}^{\mathrm{a}}$ & $R^{2}$ \\
\hline MWCNTs8 & $2.26(0.04)$ & $-4.60 \mathrm{E}+06(1.61 \mathrm{E}+05)$ & $7.80(1.36)$ & 0.03 & 0.98 \\
MWCNTs20 & $1.88(0.03)$ & $-7.79 \mathrm{E}+01(1.07 \mathrm{E}+01)$ & $2.20(0.36)$ & 0.01 & 0.98 \\
MWCNTs30 & $1.75(0.05)$ & $-2.34 \mathrm{E}+01(1.08 \mathrm{E}+01)$ & $1.65(0.42)$ & 0.01 & 0.96 \\
MWCNTs50 & $1.60(0.03)$ & $-3.35 \mathrm{E}+01(1.01 \mathrm{E}+01)$ & $1.85(0.33)$ & 0.01 & 12 \\
MWCNTs15 & $1.93(0.03)$ & $-3.74 \mathrm{E}+02(1.09 \mathrm{E}+01)$ & $2.87(0.43)$ & 0.01 & 0.98 \\
MWCNTs15A & $1.97(0.03)$ & $-7.21 \mathrm{E}+03(1.56 \mathrm{E}+02)$ & $4.31(0.81)$ & 0.02 & 12 \\
\hline
\end{tabular}

a MWSE is mean weighted square error, equal to $1 / v \sum\left[\left(q_{\text {measured }}-q_{\text {model }}\right)^{2} / q_{\text {measured }}^{2}\right]$, where $v$ is the amount of freedom; $v=N-3$ for PMM; data in parentheses represent standard deviation. 

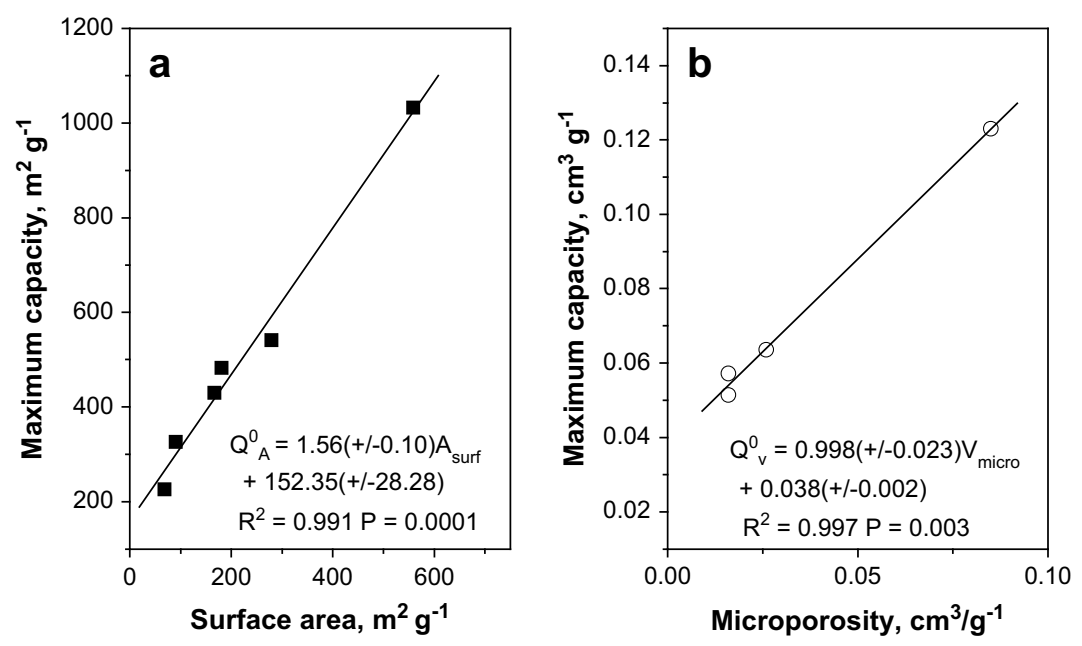

Fig. 6 - Plot of adsorption capacities obtained from PMM for TCP against surface area (a) and micropore volumes (b) of MWCNTs.

The PMM theory was developed to describe physical adsorption to microporous adsorbents and involved a pore filling mechanism and the concept of a variable adsorption potential in response to pore filling (Manes, 1980). This theory would appear to be applicable in this case since MWCNTs form bundles in aqueous media and the spaces between the tubes within the bundles can be regarded as pores, as other researchers have (Yang et al., 2006a; Pan et al., 2008). Polanyi theory is applicable for either pore filling or flat surface adsorption (Condon, 2000). Sorption of TCP correlates with both initial surface area and micropore volume of the degassed sample (Fig. 6). The molecular surface area-based value of $\mathrm{Q}^{0}\left(\mathrm{~m}^{2} \mathrm{~g}^{-1}\right)$, taking the molecular surface area of TCP to be $1.86 \mathrm{~nm}^{2}$ molecule ${ }^{-1}$ (Smejtek et al., 1996), correlates strongly with $A_{\text {surf }}$ giving a slope of about 1.56 (Fig. 6a). Likewise, the molecular volume-based value of $Q^{0}\left(\mathrm{~cm}^{3} \mathrm{~g}^{-1}\right)$, taking the liquid density of TCP to be $1.4901 \mathrm{~g} \mathrm{~cm}^{-3}$ (Lide, 2004), correlates well with $\mathrm{V}_{\text {micro }}$ giving a slope of about 0.997 (Fig. 6b). These results suggest that TCP was mainly adsorbed onto the surface and within the pores of MWCNTs bundles or aggregates which is consistent with previous reports (Yang and Xing, 2007; Pan et al., 2008).

Considering the sorption properties of the above MWCNTs we choose MWCNTs15 and MWCNTs15A to represent asgrown and nitric acid oxidation treated MWCNTs for a comparison study on $\mathrm{Cu}$ (II) effect on the sorption of TCP below.

\subsection{Adsorption of $\mathrm{Cu}(\mathrm{II})$}

Adsorption of $\mathrm{Cu}$ (II) by MWCNTs15 and MWCNTs15A is very fast and increased with $\mathrm{pH}$ in the range $\mathrm{pH} 3-6$ (Fig. 7). The increase of $\mathrm{Cu}$ (II) sorption can be ascribed to the ionizable surface charge of MWCNTs. The isoelectric point was 2.85 and
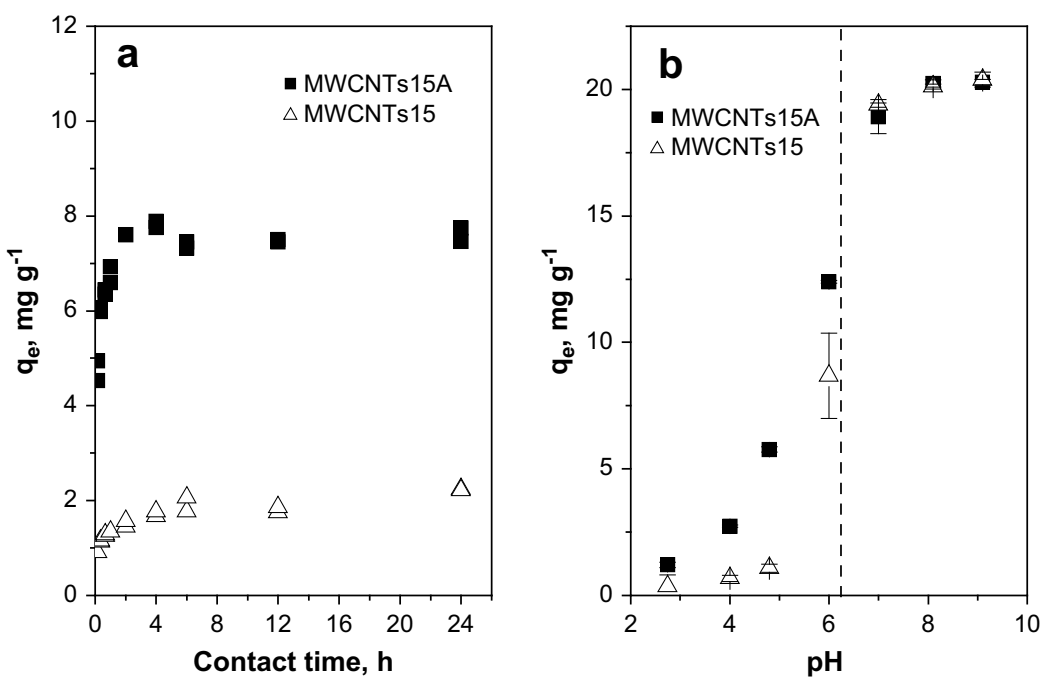

Fig. 7 - Effects of contact time (a, $10 \mathrm{mg}$ of MWCNTs and $30 \mathrm{mg} \mathrm{L}^{-1}$ of Cu(II) in $20 \mathrm{~mL}$ of $0.01 \mathrm{M} \mathrm{NaNO}_{3}$ at pH 5) and pH (10 mg of MWCNTs and $30 \mathrm{mg} \mathrm{L}^{-1}$ of $\mathrm{Cu}$ (II) in $20 \mathrm{~mL}$ of $0.01 \mathrm{M} \mathrm{NaNO}_{3}$ react for 24 hours) on sorption of Cu(II) by MWCNTs15A and MWCNTs15 (the dashed line represents the hydrolysis and precipitation of $\mathrm{Cu}$ (II), which cannot reflect the real adsorption). 

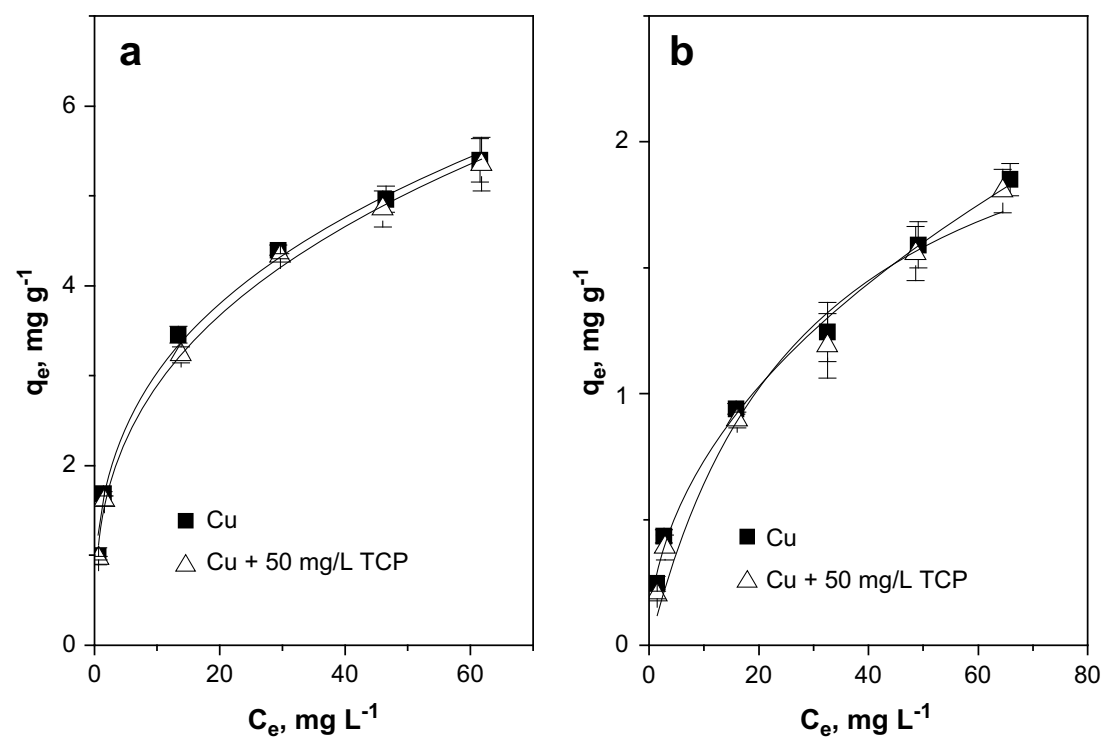

Fig. 8 - LM fit of sorption isotherms of Cu(II) on MWCNTs15A (a) and MWCNTs15 (b).

4.86 for nitric oxidized and as-grown MWCNTs, respectively (Wu, 2007), which suggests that the surfaces of oxidized and as-grown MWCNTs were negatively charged at solution $\mathrm{pH}>2.85$ and $>4.86$. The negatively charged surfaces of MWCNTs favor the adsorption of $\mathrm{Cu}(\mathrm{II})$. The increased sorption of MWCNTs15A is larger than that of MWCNTs15 over the $\mathrm{pH}$ range of 3-5, which can also be ascribed to the lower isoelectric point. Over the $\mathrm{pH}$ range of $6-9$, the adsorption increased rapidly due to the combined role of adsorption and precipitation (Li et al., 2003b). Over the $\mathrm{pH}$ range of $7-9$, the precipitation of $\mathrm{Cu}$ (II) was dominated, making true adsorption studies impossible.

Adsorption isotherms of $\mathrm{Cu}(\mathrm{II})$ were constructed at $\mathrm{pH} 4$ (Fig. 8). The isotherms were fit well by the LM and the fitting parameters are given in Table 4 . This result is consistent with the studies on the sorption of $\mathrm{Cu}^{2+}, \mathrm{Pb}^{2+}$ and $\mathrm{UO}_{2}^{2+}$ by CNTs which can be described by Langmuir model (Wu, 2007; Li et al., 2002; Schierz and Zanker, 2009). The total determined oxygen contents of MWCNTs15A and MWCNTs15 by XPS were $3.92 \%$ and $1.52 \%$, respectively, and the sorption capacities were $5.26 \mathrm{mg} \mathrm{g}^{-1}$ and $2.35 \mathrm{mg} \mathrm{g}^{-1}$, respectively, suggesting that the sorption capacities of MWCNTs15A and MWCNTs15 were roughly positively correlated with their total oxygen contents. These results implied that complexation of $\mathrm{Cu}$ (II) by oxygen-

Table 4 - Results of LM fit to Cu(II) sorption isotherms by MWCNTs.

\begin{tabular}{lcccccc} 
Carbons & $\begin{array}{c}\mathrm{TCP} \\
\left(\mathrm{mg} \mathrm{L}^{-1}\right)\end{array}$ & $\begin{array}{c}\mathrm{Q}^{0} \\
\left(\mathrm{mgg}^{-1}\right)\end{array}$ & $\begin{array}{c}b \\
\left(\mathrm{~L} \mathrm{mg}^{-1}\right)\end{array}$ & MWSE & $R^{2}$ & $n$ \\
\hline MWCNTs15A & 0 & 5.26 & 0.25 & 0.05 & 0.98 & 18 \\
& 50 & 5.35 & 0.21 & 0.05 & 0.98 & 18 \\
MWCNTs15 & 0 & 2.35 & 0.04 & 0.04 & 0.98 & 18 \\
& 50 & 2.49 & 0.04 & 0.03 & 0.99 & 18 \\
\hline
\end{tabular}

containing groups on the outermost graphene surface and defect sites was main sorption mechanism of $\mathrm{Cu}$ (II).

\subsection{XAS study of $\mathrm{Cu}$ (II) adsorption}

The nitric acid oxidation treatment introduced oxygencontaining groups, mainly carboxylic groups, which increased the adsorption of $\mathrm{Cu}$ (II) via the formation of outer- and inner-sphere complexes. The coordination environment around adsorbed $\mathrm{Cu}(\mathrm{II})$ is revealed by XAS. As previously observed by Frenkel et al. (2000), XANES spectra of adsorbed $\mathrm{Cu}$ (II) show a very weak peak just before the edge jump corresponding to $1 \mathrm{~s} \rightarrow 3 \mathrm{~d}$ (Fig. 9a and b). The pre-edge peak is sensitive to the presence of a center of symmetry, and its intensity increases with distortions that remove this center of symmetry. The first derivative of XANES shows two different inflections corresponding to derivative peaks at 8.979 ( $\alpha$ peak) and $8.984 \mathrm{keV}$ ( $\beta$ peak). The intensity of the $\alpha$ peak is influenced by the degree of axial distortion and the covalence of equatorial ligands bonded to $\mathrm{Cu}(\mathrm{II})$ ions (Hahn et al., 1982), thus providing information about the $\mathrm{Cu}$ (II) binding environment. The decreased $\alpha$ peak intensity for $\mathrm{Cu}$ (II)-MWCNTs15A compared to aqueous $\mathrm{Cu}\left(\mathrm{NO}_{3}\right)_{2}$ (the inset of Fig. 9b) suggests that the stronger field water molecules in the tetragonal plane exchanged with organic ligands (carboxylic and hydroxylic functions) from MWCNTs15A, and also suggests that adsorbed $\mathrm{Cu}$ (II) is sterically hindered due to its three-dimensional structure. When $\mathrm{Cu}$ (II) approaches, it cannot bind in the equatorial plane with the same degree of angular overlap as water.

Normalized $\mathrm{k}^{3}$-weighted EXAFS spectra of $\mathrm{Cu}(\mathrm{II})-\mathrm{MWCNTs} 15 \mathrm{~A}$ and its corresponding radial structural function derived from Fourier transformation are presented in Fig. 9c and d. The strongest radial structural function derived from Fourier transformation of EXAFS spectra occurring at $1.53 \AA$ corresponded to first $\mathrm{Cu}$ (II)-O shell 

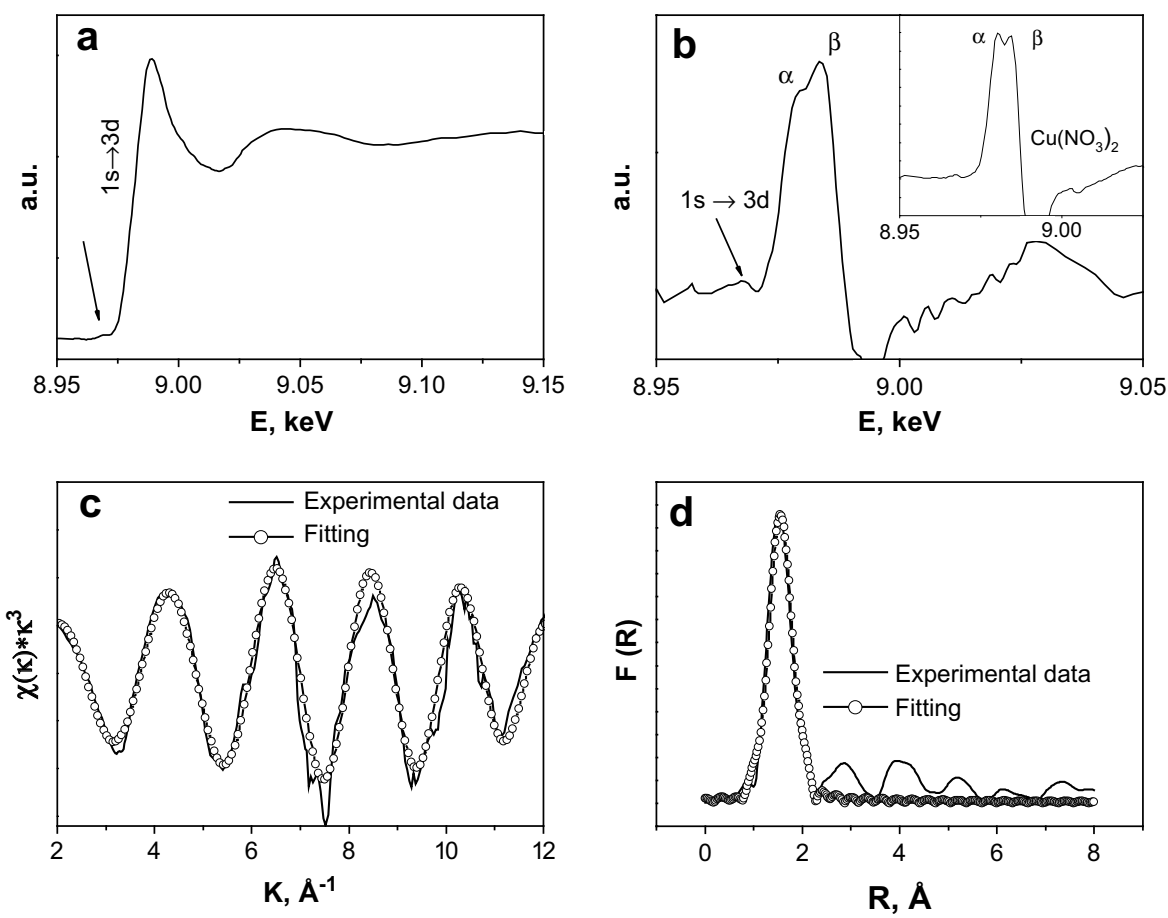

Fig. 9 - Normalized XANES spectra (a), corresponding first derivatives (b), EXAFS spectra ( $\chi$-function) (c), and Fourier transform of EXAFS (d) spectra of Cu(II)-MWCNTs15A (10 mg of MWCNTs15A and $65 \mathrm{mg} \mathrm{L}^{-1}$ of Cu(II) in $20 \mathrm{~mL}$ of $0.01 \mathrm{M}$ $\mathrm{NaNO}_{3}$ react for 24 hours at pH 4). Solid lines represent the experimental data and open circles correspond to the lines of best fitting.

(Fig. 9d). The best fit of this peak leads to 4.14 equatorial oxygen atoms at $1.94 \AA$, 2.64 axial oxygen atoms at $2.20 \AA$ for $\mathrm{Cu}(\mathrm{II})-\mathrm{MWCNTS15A}$. The data are consistent with those obtained from XANES (i.e., a slightly distorted octahedral coordination around $\mathrm{Cu}(\mathrm{II})$ sorption onto MWCNTs15A) involving $\mathrm{Cu}$ (II) (Flogeac et al., 2004). The results of four short equatorial bonds and two elongated axial bonds were due to the Jahn-Teller effect of the $\mathrm{Cu}(\mathrm{II})-\mathrm{O}$ clusters. The results suggest that $\mathrm{Cu}$ (II) complexes were formed on MWCNTs15A through carboxylic and hydroxylic groups.

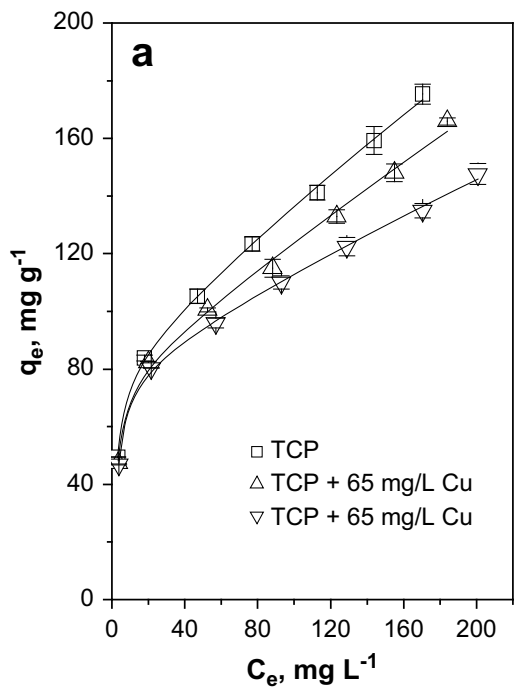

The XAS spectra of MWCNTs15 were difficult to resolve due to the low concentration of adsorbed $\mathrm{Cu}$ (II) compared to MWCNTs15A.

\subsection{Competitive sorption between $\mathrm{Cu}(\mathrm{II})$ and TCP}

The effect of $\mathrm{Cu}$ (II) on TCP sorption was evaluated by adding TCP and various amounts of $\mathrm{Cu}(\mathrm{II})$ simultaneously to MWCNTs15A or MWCNTs15 suspensions at $\mathrm{pH}$ 4. Sorption of TCP by MWCNTs15A decreased markedly, while the sorption

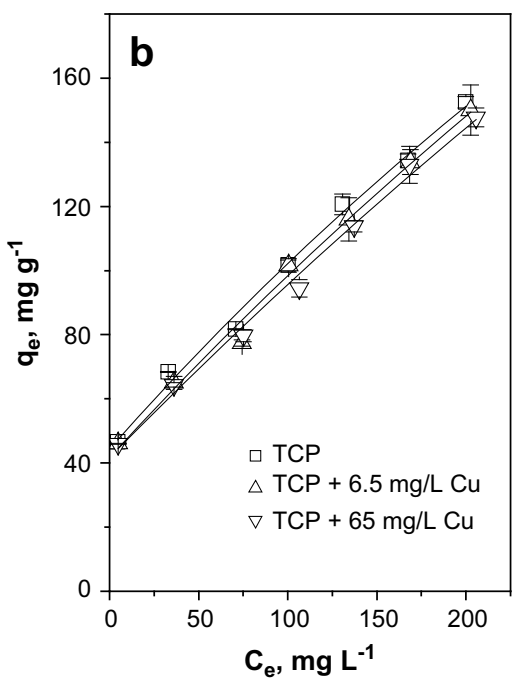

Fig. 10 - Effect of $\mathrm{Cu}$ (II) on the sorption of TCP onto MMCNT15A (a) and MMCNT15 (b) (Symbols represent experimental data, and lines represent the fitting of PMM). 
Table 5 - The $K_{d}$ values $\left(\mathrm{L} \mathrm{g}^{-1}\right)$ of TCP on MWCNTs as affected by $\mathbf{C u}\left(\right.$ II) ${ }^{\mathrm{a}}$

\begin{tabular}{|c|c|c|c|c|c|c|}
\hline \multirow{4}{*}{$\begin{array}{l}\text { Initial conc. } \\
\left(\mathrm{mgL} \mathrm{L}^{-1}\right)\end{array}$} & \multicolumn{3}{|c|}{ MWCNTs15A } & \multicolumn{3}{|c|}{ MWCNTs15 } \\
\hline & $K_{\mathrm{d}}^{1}$ & $K_{\mathrm{d}}^{2}$ & $K_{\mathrm{d}}^{2}$ & $K_{\mathrm{d}}^{1}$ & $\mathrm{~K}_{\mathrm{d}}^{2}$ & $K_{\mathrm{d}}^{2}$ \\
\hline & $\mathrm{Cu}(\mathrm{II})$ & $\mathrm{Cu}(\mathrm{II})$ & $\mathrm{Cu}(\mathrm{II})$ & $\mathrm{Cu}(\mathrm{II})$ & $\mathrm{Cu}(\mathrm{II})$ & $\mathrm{Cu}(\mathrm{II})$ \\
\hline & 0 & $\begin{array}{l}6.5 \mathrm{mg} \\
\mathrm{L}^{-1}\end{array}$ & $65 \mathrm{mg}$ & 0 & $\begin{array}{c}6.5 \mathrm{mg} \\
\mathrm{L}^{-1}\end{array}$ & $65 \mathrm{~L}^{-1}$ \\
\hline 30 & 15.24 & 13.34 & 12.92 & 10.37 & 9.63 & 9.38 \\
\hline 50 & 4.7 & 4.47 & 4.06 & 2.07 & 1.89 & 1.80 \\
\hline 100 & 2.25 & 1.9 & 1.74 & 1.15 & 1.04 & 1.06 \\
\hline 150 & 1.6 & 1.3 & 1.21 & 1.01 & 1.01 & 0.94 \\
\hline 200 & 1.23 & 1.05 & 0.95 & 0.92 & 0.86 & 0.83 \\
\hline 250 & 1.11 & 0.96 & 0.79 & 0.85 & 0.79 & 0.79 \\
\hline
\end{tabular}

of TCP by MWCNTs15 was only slightly suppressed, if at all, when 6.5 or $65 \mathrm{mgL}^{-1}$ of $\mathrm{Cu}$ (II) were present (Fig. 10). In addition, competitive sorption was greater at higher than at lower TCP concentrations. The impact of $\mathrm{Cu}$ (II) on TCP sorption was expressed as $\left(K_{d}^{2}-K_{d}^{1}\right) / K_{d}^{1}$, where $K_{d}^{2}$, and $K_{d}^{1}$ correspond to the distribution coefficients (equal to the ratio $q_{\mathrm{e}} / \mathrm{C}_{\mathrm{e}}$ ) of TCP with and without $\mathrm{Cu}(\mathrm{II})$, respectively (Table 5). The presence of $\mathrm{Cu}$ (II) at concentrations of $6.5 \mathrm{mgL}^{-1}$ and $65 \mathrm{mg} \mathrm{L}^{-1}$ decreased the sorption of TCP onto MWCNTs15A by $15 \%$ and $30 \%$, respectively, and less than $10 \%$ onto MWCNTs15, respectively. In contrast, co-adsorption of TCP at concentration of $50 \mathrm{mg} \mathrm{L}^{-1}$ had little effect on the sorption of $\mathrm{Cu}$ (II) on MWCNTs15 and MWCNTs15A (Fig. 8).

\section{Conclusions}

TCP may undergo both adsorption on MWCNT surfaces and condensation in the pore spaces within bundles of individual MWCNTs. This is supported by the application of PMM and strong correlation of sorption capacity with surface areas and pore volumes, as well as the results of other studies (Yang and Xing, 2007; Pan et al., 2008). It is widely known that CNTs unmodified with surfactants or covalently attached groups exist in a bundled state in water due to strong van der Waals interactions between the tubes. It is reasonable that TCP can be condensed in the pore spaces between tubes although no desorption hysteresis was observed (Fig. S2, Supporting information). As condensation progresses, TCP-CNT interactions compete with CNT-CNT interactions, causing the bundles to swell slightly and facilitating further condensation. Nitric acid treatment introduces hydrophilic functional groups that reduce CNT-CNT interactions. Copper acts by cross-linking functional groups on adjacent tubes, creating a more tightly knit bundle and suppressing condensation of TCP. Nitric acid treatment promotes competition with $\mathrm{Cu}$ (II) because it creates more cross-linking opportunities.

Furthermore, the suppression of TCP sorption by $\mathrm{Cu}$ (II) can be explained by assuming that $\mathrm{Cu}$ (II) forms strong outer- and inner-sphere complexes at hydrophilic defect sites (Fig. 9), which provide steric hindrance to TCP binding sites due to the sizable hydration sphere of adsorbed $\mathrm{Cu}(\mathrm{II})$. This "crowding out" hypothesis is supported by the results of Chen et al.
(2007) who found that $\mathrm{Cu}(\mathrm{II})$ suppresses sorption of both hydrogen bonding solutes (2,4-dichlorophenol) and apolar solutes (1,2-dichlorobenzene and naphthalene) on wood char, whose primary structure, analogous to CNTs with defects, is the graphene sheet rimmed by oxygen functional groups. Just as with CNTs, competition appears to be relatively greater at higher than at lower concentration of the principal solute (Chen et al., 2007).

\section{Acknowledgments}

This work was funded by the National Natural Science Foundation of China (grant number: 20707037) with further support from CSREES, U.S. Department of Agriculture.

\section{Appendix. \\ Supplementary data}

Two figures (Fig. S1 - Fit of FM (a), LM (b), DMM (c) and DLM (d) to the sorption of TCP onto six MWCNTs; Fig. S2 - Effect of $\mathrm{Cu}$ (II) on the desorption of TCP from MWCNTs15A (a, without $\mathrm{Cu}$ (II) adsorbed; b, with $6.5 \mathrm{mgL}^{-1} \mathrm{Cu}(\mathrm{II})$ simultaneously adsorbed) and MWCNTs15 (c, without $\mathrm{Cu}$ (II) adsorbed; d, with $6.5 \mathrm{mg} \mathrm{L}^{-1} \mathrm{Cu}$ (II) simultaneously adsorbed)).

Supplementary data associated with this article can be found in the online version, at doi:10.1016/j.watres.2009.03.002.

\section{R E F E R E N C E S}

Chaliha, S., Bhattacharyya, K.G., 2008. Catalytic wet oxidation of 2-chlorophenol, 2,4-dichlorophenol and 2,4,6-trichlorophenol in water with Mn(II)-MCM41. Chemical Engineering Journal 139, 575-588.

Chen, J.Y., Zhu, D.Q., Sun, C., 2007. Effect of heavy metals on the sorption of hydrophobic organic compounds to wood charcoal. Environmental Science and Technology 41, 2536-2541.

Chin, C.J.M., Shih, L.C., Tsai, H.J., Liu, T.K., 2007. Adsorption of oxylene and $p$-xylene from water by SWCNTs. Carbon 45, 12541260.

Cho, H., Smith, B.A., Wnuk, J.D., Fairbrother, D.H., Ball, W.P., 2008. Influence of surface oxides on the adsorption of naphthalene onto multiwalled carbon nanotubes. Environmental Science and Technology 42, 2899-2905.

Coleman, K.S., Bailey, S.R., Fogden, S., Green, M.L.H., 2003. Functionalization of single-walled carbon nanotubes via the Bingel reaction. Journal of the American Chemical Society 125 , 8722-8723.

Condon, J.B., 2000. Equivalency of the Dubinin-Polany equations and the $\mathrm{QM}$ based sorption isotherm equation. Part $\mathrm{B}$. Simulations of heterogeneous surfaces. Microporous and Mesoporous Materials 38, 377-383.

Dai, J.Y., Xu, M.Q., Chen, J.P., Yang, X.P., Ke, Z.S., 2007. PCDD/F, $\mathrm{PAH}$ and heavy metals in the sewage sludge from six wastewater treatment plants in Beijing, China. Chemosphere 66, 353-361.

Datsyuk, V., Kalyva, M., Papagelis, K., Parthenios, J., Tasis, D., Siokou, A., Kallitsis, S.I., Galiotis, C., 2008. Chemical oxidation of multiwalled carbon nanotubes. Carbon 46, 833-840. 
Daughney, C.J., Fein, J.B., 1997. Aqueous complexation of cadmium, lead, and copper by 2,4,6-trichlorophenolate and pentachlorophenolate. Geochimica et Cosmochimica Acta 61, 719-729.

Flogeac, K., Gullion, E., Aplincourt, M., 2004. Surface complexation of copper(II) on soil particles, EPR and XAFS studies. Environmental Science and Technology 38, 3098-3103.

Freundlich, H.M.F., 1906. Over the adsorption in solution. Journal of Physical Chemistry 57, 385-470.

Frenkel, A., Korshin, G.V., Ankudinov, A.L., 2000. XANES study of $\mathrm{Cu}^{2+}$-binding sites in aquatic humic substances.

Environmental Science and Technology 34, 2138-2142.

Gotovac, S., Honda, H., Hattori, Y., Takahashi, K., Kanoh, H., Kaneko, K., 2007. Effect of nanoscale curvature of singlewalled carbon nanotubes on adsorption of polycyclic aromatic hydrocarbons. Nano Letters 7, 583-587.

Hahn, J.E., Scott, R.A., Hodgson, K.O., Doniach, S., Desjardins, S.R., Solomon, E.I., 1982. Observation of an electric quadrupole transition in the X-ray absorption spectrum of a $\mathrm{Cu}(\mathrm{II})$ complex. Chemical Physics Letters 88, 595-598.

Hsin, Y.L., Lai, J.Y., Hwang, K.C., Lo, S.C., Chen, F.R., Kai, J.J., 2006. Rapid surface functionalization of iron-filled multi-walled carbon nanotubes. Carbon 44, 3328-3335.

Keith, L.H., Telliard, W.A., 1979. ES\&T special report: priority pollutants: part I - a perspective view. Environmental Science and Technology 13, 416-423.

Kim, S.D., Kim, J.W., Im, J.S., Kim, Y.H., Lee, Y.S., 2007. Oxidation of multiwalled carbon nanotubes by nitric acid. Journal of Fluorine Chemistry 128, 60-64.

Li, Y.H., Wang, S., Wei, J., Zhang, X., Luan, Z., Wu, D., Wei, B., 2002. Lead adsorption on carbon nanotubes. Chemical Physics Letters 357, 263-266.

Li, Y.H., Wang, S., Luan, Z., Ding, J., Xu, C., Wu, D., $2003 a$. Adsorption of cadmium(II) from aqueous solution by surface oxidized carbon nanotubes. Carbon 41, 1057-1062.

Li, Y.H., Ding, J., Luan, Z.K., Di, Z.C., Zhu, Y.F., Xu, C.L., Wu, D.H., Wei, B.O., 2003b. Competitive adsorption of $\mathrm{Pb}^{2+}, \mathrm{Cu}^{2+}$ and $\mathrm{Cd}^{2+}$ ions from aqueous solutions by multiwalled carbon nanotubes. Carbon 41, 2787-2792.

Lide, D.R., 2004. Handbook of Chemistry and Physics, eighty fifth ed. CRC Press, Boca Raton, FL.

Langmuir, I., 1916. The adsorption of gases on plane surface of glass, mica and platinum. Journal of the American Chemical Society 40, 1361-1368.

Long, R.Q., Yang, R.T., 2001. Carbon nanotubes as superior sorbent for dioxin removal. Journal of the American Chemical Society 123, 2058-2059.

Lu, C., Chung, Y.L., Chang, K.F., 2005. Adsorption of trihalomethanes from water with carbon nanotubes. Water Research 39, 1183-1189.

Lu, C., Chiu, H., 2006. Adsorption of zinc(II) from water with purified carbon nanotubes. Chemical Engineering Science 61, 1138-1145.

Manes, M., 1980. The Polanyi adsorption potential theory and its application to adsorption from water solution onto activated carbon. In: Suffet, I.H., McGuire, M.J. (Eds.), Activated Carbon Adsorption of Organics from the Aqueous Phase. Ann Arbor Science, Michigan, pp. 43-63.

Makinen, P.M., Theno, T.J., Ferguson, J.F., Ongerth, J.E., Puhakka, P.M., 1993. Chlorophenol toxicity removal and monitoring in aerobic treatment: recovery from process upsets. Environmental Science and Technology 27, 1434-1439.

Mueller, J.G., Chapmanm, P.J., Pritchard, P.H., 1989. Creosotecontaminated sites. Their potential for bioremediation. Environmental Science and Technology 23, 1197-1201.

NCI, 1979. Bioassay of 2,4,6-trichlorophenol for possible carcinogenicity (CAS No. 88-06-2), Technical Report Series No 155, DHEW (NIH) Publication No. 79-1711, National Institutes of Health, Bethesda, MD, pp. 131.
Pan, B., Lin, D., Mashayekhi, H., Xing, B., 2008. Adsorption and hysteresis of bisphenol A and $17 \alpha$-ethinyl estradiol on carbon nanomaterials. Environmental Science and Technology 42, 5480-5485.

Pei, Z.G., Shan, X.Q., Liu, T., Xie, Y.N., Wen, B., Zhang, S.Z., Khan, S.U., 2006. Sorption of $p$-nitrophenol on two Chinese soils as affected by copper. Environmental Toxicology and Chemistry 25, 2584-2592.

Pei, Z.G., Shan, X.Q., Liu, T., Xie, Y.N., Wen, B., Zhang, S.Z., Khan, S.U., 2007. Effect of lead on the sorption of 2,4,6-trichlorophenol on soil and peat. Environmental Pollution 147, 764-770.

Rinzler, A.G., Liu, J., Dai, H., Nikolaev, P., Huffman, C.B., Rodriguez-Macias, F.J., Boul, P.J., Lu, A.H., Heymann, D., Colbert, D.T., Lee, R.S., Fischer, J.E., Rao, A.M., Eklund, P.C., Smalley, R.E., 1998. Large-scale purification of single-wall carbon nanotubes, process, product, and characterization. Applied Physics A 67, 29-37.

Sander, M., Pignatello, J.J., 2005. Characterization of charcoal adsorption sites for aromatic compounds: insights drawn from single-solute and bi-solute competitive experiments. Environmental Science and Technology 39, 1606-1615.

Schierz, A., Zanker, H., 2009. Aqueous suspensions of carbon nanotubes: surface oxidation, colloidal stability and uranium sorption. Environmental Pollution 157, 1088-1094.

Smejtek, P., Blochel, A., Wang, S., 1996. Hydrophobicity and sorption of chlorophenolates to lipid membranes. Chemosphere 33, 177-201.

Sprovieri, M., Feo, M.L., Prevedello, L., Manta, D.S., Sammartino, S., Tamburrino, S., Marsella, E., 2007. Heavy metals, polycyclic aromatic hydrocarbons and polychlorinated biphenyls in surface sediments of the Naples harbour (southern Italy). Chemosphere 67, 998-1009.

Suntio, L.R., Shiu, W.Y., Mackay, D., 1988. A review of the nature and properties of chemicals present in pulp mill effluents. Chemosphere 17, 1249-1290.

Wang, X.K., Chen, G., Hu, W., Ding, A., Xu, D., Zhou, X., 2005. Sorption of ${ }^{243} \mathrm{Am}$ (III) to multiwall carbon nanotubes. Environmental Science and Technology 39, 2856-2860.

Wightman, P., Fein, J.B., 1999. Experimental study of 2,4,6trichlorophenol and pentachlorophenol solubilities in aqueous solutions: derivation of a speciation-based chlorophenol solubility model. Applied Geochemistry 14, 319-331.

$\mathrm{Wu}, \mathrm{C} . \mathrm{-H} ., 2007$. Studies of the equilibrium and thermodynamics of the adsorption of $\mathrm{Cu}^{2+}$ onto as-produced and modified nanotubes. Journal of Colloid and Interface Science 311, 346-388.

Xing, B.S., Pignatello, J.J., 1997. Dual-mode sorption of lowpolarity compounds in glassy poly(vinyl chloride) and soil organic matter. Environmental Science and Technology 31, 792-799.

Yang, K., Zhu, L.Z., Xing, B.S., 2006a. Adsorption of polycyclic aromatic hydrocarbons by carbon nanomaterials. Environmental Science and Technology 40, 1855-1861.

Yang, K., Wang, X.L., Zhu, L.Z., Xing, B.S., 2006b. Competitive sorption of pyrene, phenanthrene, and naphthalene on multiwalled carbon nanotubes. Environmental Science and Technology 40, 5804-5810.

Yang, K., Xing, B.S., 2007. Desorption of polycyclic aromatic hydrocarbons from carbon nanomaterials in water. Environmental Pollution 145, 529-537.

Ying, Y.M., Saini, R.K., Liang, F., Sadana, A.K., Billups, W.E., 2003. Functionalization of carbon nanotubes by free radicals. Organic Letters 5, 1471-1473.

Yoshida, K., Shigeoka, T., Yamamuchi, F., 1987. Evaluation of aquatic environmental fate of 2,4,6-trichlorophenol with a mathematical model. Chemosphere 16, 2531-2544.

Zhou, W.M., Fu, D.Q., Sun, Z.G., 1991. Determination of black list of China's priority pollutants in water. Research of Environmental Sciences 4, 912-915. 